
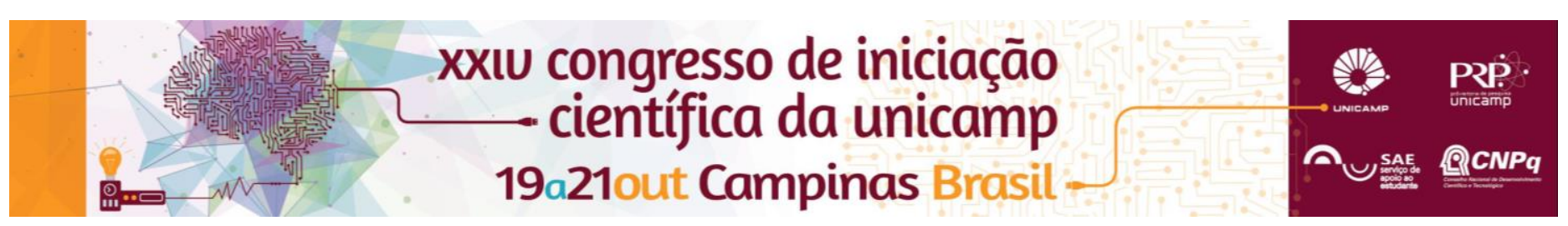

\title{
Implementação de Placa de Contagem de Pulsos via USB
}

\author{
Pedro Henrique S. Oliveira* (ph.telecom@outlook.com), Kevin N. Moreira (kevinmoreira@hotmail.com), Cristiano \\ M. Gallep (gallep@ft.unicamp.br).
}

\section{Resumo}

A fim de expandir a instrumentação do Laboratório de Fotônica Aplicada, este trabalho visa a implementação de uma placa de aquisição de dados de baixo custo, provenientes de pulsos TTL de PMT's (Photon multiplier tubes- Válvulas fotomultiplicadoras), utilizando ambiente de prototipagem Arduino, de forma que possa ser uma alternativa às placas de alto nível (i.e., Hamamatsu) para realizar testes de medição de emissão de luz ultra-fraca (UWPE).

Palavras-chave: Arduino, placa de contagem, fóton.

\section{Introdução}

Este projeto de Iniciação Científica e Tecnológica visa implementar uma plaça de aquisição de dados microcontrolada via USB para uso como sistema alternativo de fóton-contagem, à partir de válvulas fotomultiplicadoras para detecção de emissão de luz espontânea ultrafraca de amostras no período de germinação.

O principal objetivo em desenvolver uma aplicação das medições das emissões ultra-fracas de fótons de sementes em germinação é usá-las como indicador biológico, tornando-se uma ferramenta viável para controle e monitoramento de uma possível contaminação ambiental. Por isso, torna-se necessário o desenvolvimento de uma instrumentação aplicada a estas medições de bioluminescência ultra-fraca, tanto de natureza espontânea como estimuladas, para uso com amostras biológicas de tamanho reduzido, tais como sementes em germinação e bactérias em crescimento.

\section{Resultados e Discussão}

De acordo com o sistema alternativo para medição de fóton-contagem proposto em [1], foi montada uma placa de hardware com prototipagem Arduino e alguns componentes e dispositivos eletrônicos. Um código fonte escrito em linguagem $C$ para programação do microcontrolador ATMega328P foi obtido além de um código escrito em linguagem Processing para controle e interface do sistema. A comunicação via canal RS232 tornou-se obsoleta uma vez que a troca de informações entre a placa e o microcontrolador ocorrem via USB.

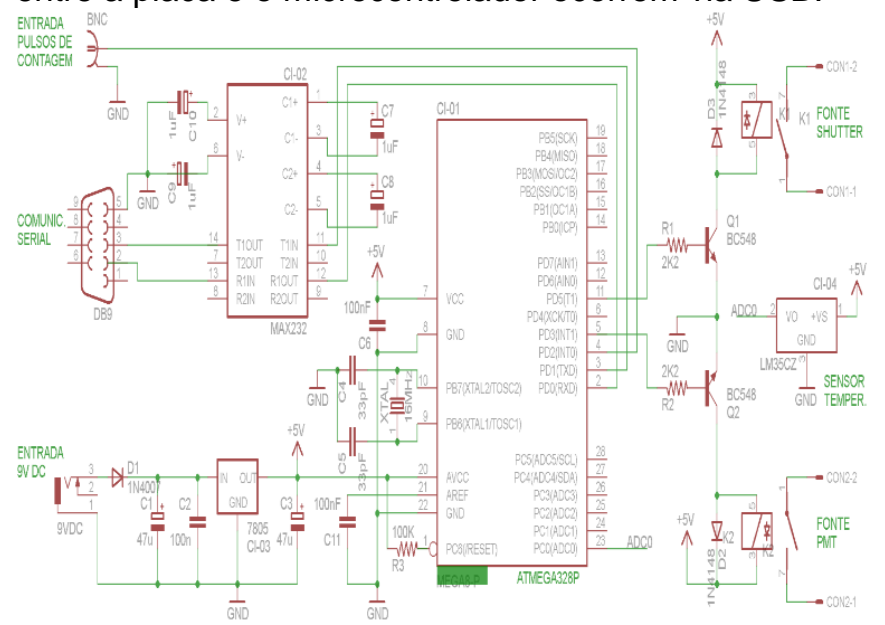

Figura 1. Esquema elétrico proposto.

DOI: 10.19146/pibic-2016-51175
Testes de medição de ruído foram realizados e através do Processing ou da própria IDE do Arduino o usuário escolhe o intervalo de integração e a quantidade de loops que serão realizados, o que determina o tempo total de medição. Após análise estatística, verificou-se que os pontos obtidos pela placa de contagem estão em média $4 \%$ abaixo dos pontos obtidos com a placa de contagem Hamamatsu.

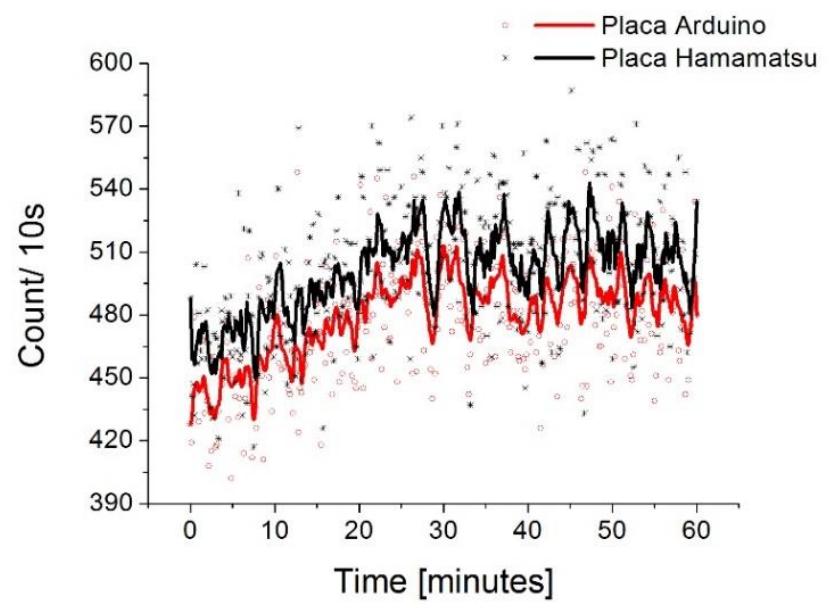

Figura 2. Teste de ruído com a placa Arduino e a placa de contagem Hamamtsu.

\section{Conclusões}

A placa de contagem com o Arduino apresentouse como uma boa alternativa de baixo custo em comparação com as placas Hamamatsu existentes no mercado. Seu desempenho inferior pode ser devido à ausência de um estágio de amplificação do sinal, como proposto em [2], por diferenças na taxa de amostragem ou pela diferença entre a impedância das placas.

Agradecimentos

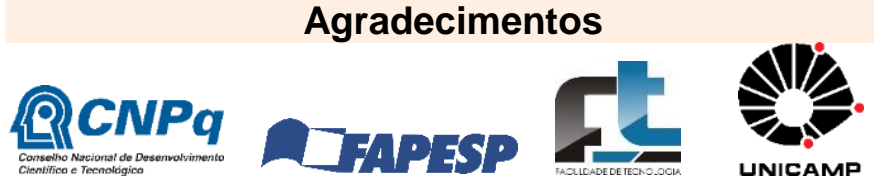

Laboratório de Fotônica Aplicada (LaFA)

\footnotetext{
$\overline{1}$ BERTOGNA, Eduardo G. Projeto, construção e aplicações de câmara escura portátil para medidas de Bioluminescência ultra-fraca. Tese de Doutorado. Campinas-SP 2013;

2 EDITORIAL COMMITTEE HAMAMATSU PHOTONICS K. K. Photomultiplier tubes, basics and applications, $3^{\circ}$ edition. Technical report. Japan, 2007. 323 p.
} 